\title{
Exploring Future Water Shortage for Large River Basins under Different Water Allocation Strategies
}

\author{
Dan Yan ${ }^{1,2} \cdot$ Mingtian Yao ${ }^{1} \cdot$ Fulco Ludwig $^{1}$ • \\ Pavel Kabat $^{1}$ • He Qing Huang ${ }^{2}$ • Ronald W. A. Hutjes ${ }^{1}$ • \\ Saskia E. Werners ${ }^{1}$
}

Received: 4 August 2017 / Accepted: 26 March 2018 /

Published online: 14 April 2018

(C) The Author(s) 2018

\begin{abstract}
Climate change and socio-economic development increase variations in water availability and water use in the Pearl River Basin (PRB), China. This can potentially result in conflicts over water resources between water users, and cause water shortage in the dry season. To assess and manage water shortage in the PRB, we first explored two water availability and three water use scenarios. Next, four different strategies to allocate water were defined. These water allocation strategies prioritized upstream water use, Pearl River Delta water use, irrigation water use, and manufacturing water use, respectively. The impact of the four strategies on water use and related economic output was assessed under different water availability and water use scenarios. Results show that almost all the regions in the PRB are likely to face water shortage under the four strategies. The increasing water demand contributes twice as much as the decreasing water availability to water shortage. All four water allocation strategies are insufficient to solve the water scarcity in the PRB. The economic losses differ greatly under the four water allocation strategies. Prioritizing the delta region or manufacturing production would result in lower economic losses than the other two strategies. However, all of them are rather extreme strategies. Development of water resources management strategies requires a compromise between different water users.
\end{abstract}

Keywords Water resources allocation $\cdot$ Water shortage $\cdot$ Climate change $\cdot$ Socio-economic development $\cdot$ Pearl River basin

Electronic supplementary material The online version of this article (https://doi.org/10.1007/s11269-0181975-8) contains supplementary material, which is available to authorized users.

Dan Yan

yandan0918@gmail.com

1 Water Systems and Global Change, Wageningen University \& Research, PO Box 47, 6700 AA Wageningen, The Netherlands

2 Key Laboratory of Water Cycle and Related Land Surface Processes, Institute of Geographic Sciences and Natural Resources Research, CAS, 11A Datun Road, Chaoyang District, Beijing 100101, China 


\section{Introduction}

Water is essential for human survival and all activities (Oki and Kanae 2006). However, fresh water resources are unevenly distributed in time and space, which causes serious water shortage in many parts of the world (Piao et al. 2010). In addition, population growth and socio-economic development have exponentially increased global water use during the last few centuries. This intensified the competition over water resources between different regions and sectors (Liu et al. 2017). Solutions to water stress problems depend not only on water availability, but also on water management and allocation (Biswas 2004). However, water management and allocation faces major challenges due to climate change and socio-economic development (Alcamo et al. 2007).

The Pearl River is the third largest river in terms of drainage area in China (Fig. 1). It mainly flows through Yunnan, Guizhou, Guangxi, and Guangdong provinces, and enters the South China Sea through the Pearl River Delta (PRD). The Pearl River basin (PRB) is situated in a subtropical monsoon climate zone. About $80 \%$ of the streamflow occurs during the wet season. Highly uneven spatial and temporal distribution of streamflow has caused seasonal water shortages in the basin. In a previous study, we showed that discharge during the dry season is likely to reduce because of climate change (Yan et al. 2015). Without any interventions, reduced future low flows may further aggravate seasonal water shortages in the PRB.

Socio-economic development and water use differ greatly across the PRB regions. The PRD is the world's largest urban region (World Bank 2015), accounts for $12 \%$ of the total area of the PRB. In 2000, the PRD used 17.2 billion $\mathrm{m}^{3}$ water, accounting for $29.9 \%$ of the total water use of the PRB. The upstream basin, however, consists of the poorest regions in China (Jalan and Ravallion 2000). Guizhou (the part within the PRB that uses water from Pearl River tributaries) is $50 \%$ larger in area than the PRD, but only used $12 \%$ of the PRD's total water use in 2000 due to limited socio-economic activities (PRWRC 2001).

However, the poorer upstream regions have started catching up the delta since Chinese government launched the "Western Development Program" in 1999, which aimed to boost the socio-economic development in western China (Lai 2002). The program substantially

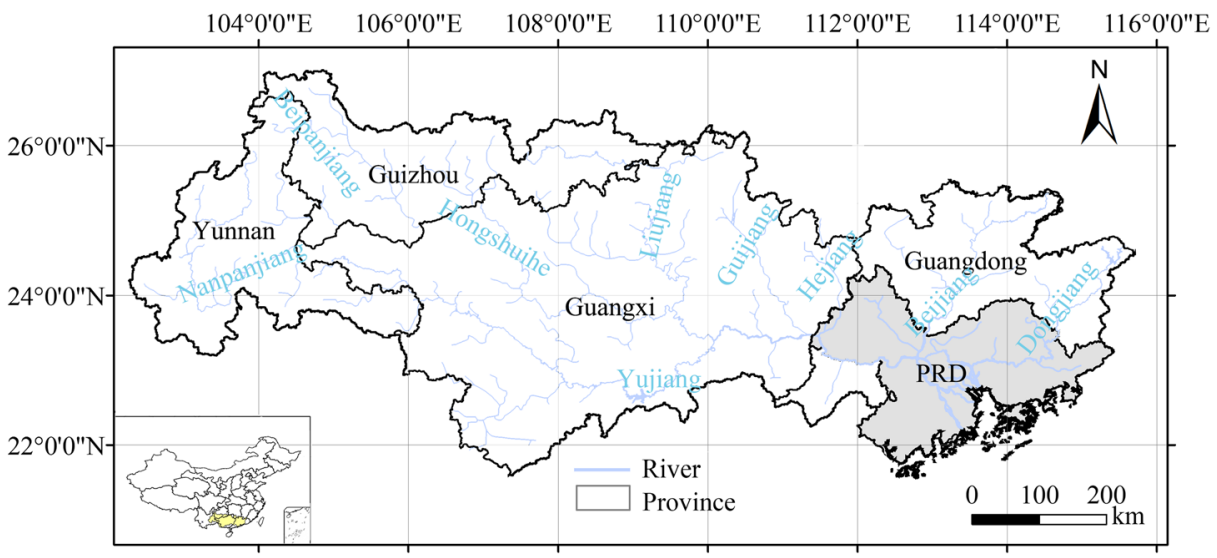

Fig. 1 Location of the Pearl River Basin. The PRB mainly covers 4 provinces (Yunnan, Guizhou, Guangxi, Guangdong) in southern China. The Pearl River Delta (PRD), which is located in Guangdong province, is the largest urban complex in the world consists 11 important cities, include Hong Kong and Macau (Hong Kong and Macau are not include in the present study) 
accelerated the economic growth, and increased water use of the upstream provinces (PRWRC 2015). This has resulted in reducing streamflow in the Pearl River, and reduced water supply to the delta (Zheng et al. 2016). In 2014, the total water use in the Pearl River basin is 61.2 billion $\mathrm{m}^{3}$, of which $28.8 \%$ was used by the PRD. Compared to 2000 , the absolute water use in the PRD increased by 0.41 billion $\mathrm{m}^{3}$, but its ratio dropped about $1.1 \%$. During the same period, water use in Guizhou increased by 0.25 billion $\mathrm{m}^{3}$, and the proportion of water used in Guizhou also had an increase of about $0.15 \%$ (PRWRC 2015). Water use in the delta is likely to gradually increase in the near future (Yao et al. 2017), while the upstream parts of the PRB would require more water for its future development. This could result in water use conflicts between upstream and downstream regions.

Saltwater intrusion may further aggravate water conflicts between upstream and downstream regions. To reduce saltwater intrusion, local authority launched the "Key Reservoirs Operational Project for Pearl River Basin" policy to reduce saltwater intrusion by releasing additional water from upstream reservoirs (Xie 2007). The implementation of this policy reduced salt intrusion to some extent, but required large amounts of fresh water from upstream, where water resources were already insufficient in some regions (Cai et al. 2011). Further implementation of this policy may exacerbate the already existing water scarcity in the upstream part of the basin.

Competition for water not only exists between upstream and downstream regions, but also exists between different water use sectors. The two major water use sector in the PRB are irrigation and industry. Irrigation water use accounted for $57 \%$ of total water consumption in 2000, but only 46\% in 2014 (PRWRC 2001; PRWRC 2015). Meanwhile, the industrial water use increased by 3 billion $\mathrm{m}^{3}$ (from $18 \%$ in 2000 to $22.7 \%$ in 2014).

Although it is clear that competition for water will increase in future, the extent of the problems, the economic impacts and possible strategies to reduce competition are still unclear. To address this knowledge gap, we focus on three different research questions:

1. How severe are water shortages during the dry season in the PRB under future climate change and socio-economic development?

2. How do the water shortages affect economic development in the PRB?

3. Can water allocation strategies alleviate competition over limited water resource in the PRB?

To answer these questions, we develop future water use scenarios using the Shared Socioeconomic Pathways (SSPs) framework (O’Neill et al. 2015). Future water availability scenarios, consistent with the Representative Concentration Pathways (RCPs) (van Vuuren et al. 2011) are adopted from our previous study (Yan et al. 2015). These scenarios are used to assess the impact of different water allocation strategies on future water shortage in the dry season.

The novelty of this paper is to present an approach to integrate water supply and use management in a changing and complex environment. In recent years, many countries paid more attention on water use management, for example, China's most stringent water resources management for water quantity and quality control (Ge et al. 2017). However, adapting to future water shortage requires considering both supply and use. Through assessing the combined effects of climate change and socio-economic development on water supply and use, and identifying water allocation strategies to alleviate competition over limited water resources in the PRB, this study represents an important contribution to integration of supply and use management. Additionally, multiple globally-consistent regional climate change and 
socio-economic development scenarios are developed and used to explore future water shortage in the PRB under different water allocation strategies in this paper. These regional scenarios provide a useful tool that works across different disciplines and different sector of society, and merging different spatial and temporal scales.

\section{Methodology}

\subsection{Water Availability and Water Use Scenarios}

Future water availability scenarios are adopted from our previous study (Yan et al. 2015). The scenarios are generated using the variable infiltration capacity (VIC) hydrological model combing five global climate models (GCMs) under RCP4.5 and 8.5. The five GCMs used are CNRM-CM5, EC-EARTH, HadGEM2-ES, IPSL-CM5A-LR, and MPI-ESM-LR. These GCMs can well represent future climate change in the PRB (Wang and Chen 2014). See Yan et al. (2015) for details on the hydrological modelling and the development of the future water availability scenarios.

Development of the water use scenarios follows the method in Yao et al. (2016), which links region-specific historical trends and future development targets with China's national SSPs scenarios (Supplementary material 1). When we refer to "SSP scenarios" below it indicates the sub-basin scenarios developed for this study, rather than the original SSP scenario descriptions (O’Neill et al. 2015).

\subsection{Water Allocation Strategies in the PRB}

Four different water allocation strategies are defined. The first two strategies reflect the competition between upstream regions and the Delta, and the others are two economicdriven strategies that reflect the competition between different water use sectors. All four strategies assume that all the requirements for domestic and environmental water use are fulfilled. Domestic water use includes urban residential water use, urban public water use, and rural residential water use. Environmental flow is calculated using a simple Tennant method (Pastor et al. 2013). Additional water to prevent saltwater intrusion is not included in the environmental flow calculation in this study.

The four strategies are:

1. upstream-prioritized (UP) strategy. The upstream region preferentially uses the amount of water as projected under water use scenarios. If its projected water use is larger than projected water availability, the upstream region would take all the available water in this region.

2. delta-prioritized (DP) strategy. In this strategy, the upstream regions release additional water to the Delta, which can satisfy irrigation and manufacturing water demand in the Delta. We had planned to satisfy water demand of the Delta first, and optimized the remaining water resources between different upstream regions. However, transferring water from downstream to upstream region over a long distance is very difficult to implement (Zhong 2004). Therefore, the DP strategy is simplified. In the new DP strategy, we assume that each upstream region releases the same absolute amount of additional water to the Delta. 
3. irrigation- prioritized (IrrP) strategy. In this strategy, the overall agricultural profit of the PRB is maximized using an open source framework for many-objective robust decision making (OpenMORDM) developed by Hadka et al. (2015). The plan with the highest agricultural profit is selected as the IrrP strategy.

4. manufacture-prioritized (ManP) strategy. This strategy is also generated by the OpenMORDM. The difference between the IrrP and ManP strategy is that the ManP strategy pursues the highest manufacturing profit.

Both the IrrP and ManP strategy are generated by the OpenMORDM. The OpenMORDM is a useful tool to help decision makers for adaptive water management in river basins (Hadka et al. 2015). Two objectives and three constraints are used in the OpenMORDM to evaluate the performance of the newly generated plans. The two objectives are to maximize profits from agricultural and manufacturing water use:

$$
\begin{gathered}
f_{\text {irr_profit }}=\max \left(\frac{1}{|S| T}\left(\sum_{j=1}^{M} \sum_{i=1}^{N} I W U_{i, j}{ }^{*} X_{i, j}{ }^{*} I_{i}\right)\right) \\
f_{\text {man_profit }}=\max \left(\frac{1}{|S| T}\left(\sum_{j=1}^{M} \sum_{i=1}^{N} \frac{M W U_{i, j} Y_{i, j}}{M S W I_{2010} \times T C_{t}}\right)\right)
\end{gathered}
$$

where $f_{\text {irr profit }}$ and $f_{\text {man profit }}$ represent profits from agricultural and manufacturing water use, 100 million international $\$ 2005 . M$ is the number of months from 2010 to $2050, N$ represents numbers of regions in the PRB, IWU $U_{i, j}$ and $M W U_{i, j}$ are the projected irrigation and manufacturing water use in the $i^{\text {th }}$ region at time $j$, million $\mathrm{m}^{3}, M S W I_{2010}$ is the manufacturing structural water use intensity in the base year $2010, \mathrm{~m}^{3} / 1000$ international $\$ 2005, X_{i}$ and $Y_{i}$ represent the percentage of irrigation and manufacturing water use, which are used by the $i^{\text {th }}$ region at time $j, I_{i}$ represents irrigation index, $S$ represents the set of all sampled climate scenarios. $T$ represents the number of years during 2010-2050.

Three constraints are used, which are the actual irrigation and manufacturing water uses should be less than the total projected irrigation and manufacturing water uses, and the total water use of all water use sectors should be less than the water availability of the PRB given as follow:

$$
\begin{gathered}
I W U_{\text {total }, j} \geq \sum_{i=1}^{N} I W U_{i, j^{*}} X_{i} \\
M W U_{\text {total }, j} \geq \sum_{i=1}^{N} M W U_{i, j^{*}} Y_{i} \\
Q_{\text {total }, j} \geq \sum_{i=1}^{N} E N V_{i, j}+\sum_{i=1}^{N} D O M_{i, j}+\sum_{i=1}^{N} I R R_{i, j} X_{i}+\sum_{i=1}^{N} M A N_{i, j^{*}} Y_{i}-\sum_{I=1}^{N} R E T_{i, j}
\end{gathered}
$$

where $Q_{\text {total, } j}$ represents water availability in the PRB at time $j, I W U_{\text {total, } j}$ and $M W U_{\text {total, }}$ ${ }_{j}$ represent the projected total irrigation and manufacture water use of the whole basin at time $j . E N V_{i, j}$ and $D O M_{i, j}$ represent environmental flow and domestic water use of the $i^{\text {th }}$ region at time $j$ respectively, $R E T_{i, j}$ is the amount of water returned by the $i^{\text {th }}$ region at time $j$, million $\mathrm{m}^{3}$. 


\subsection{Water Shortage in the PRB}

Water shortages under the four water allocation strategies are estimated for each region during the dry months when projected water use is higher than water availability. As the purpose of this study is to quantify how severe the water shortage is during the dry season, more attention is paid to the drier climate change scenario (RCP8.5), for which water shortages are likely to be more severe.

For the UP strategy, water shortage of each region is calculated according to Eqs. 6 and 7. Equation 6 is developed for regions without upstream region, for example, Yunnan.

$$
\begin{aligned}
& W D_{m}=\sum_{t=1}^{T}\left(A W_{m, t}-W U_{m, t}\right) / T \\
& W S_{m}=\left\{\begin{array}{l}
0, W D_{m}>0 \\
W D_{m}, W D_{m}<0
\end{array}\right.
\end{aligned}
$$

where $W D_{m}$ is the monthly mean difference between water availability and water use for a upstream region during 2010-2050, $W S_{m}$ represents the monthly mean water shortage for the upstream region, $m$ represents each month during a year (from January to December), $A W_{m, t}$ and $W U_{m, t}$ are water availability and water use for month $m$ in year $t, T$ represents the number of years during 2010-2050. The unit of $W D_{m}, W S_{m}, A W_{m, t}$, and $W U_{m, t}$ is million $\mathrm{m}^{3}$.

Equation 7 is developed for regions with upstream region(s), for example, Guangxi.

$$
\begin{aligned}
& W D_{m}=\sum_{t=1}^{T}\left(\sum_{x=1}^{X} E W_{m, t, x}+A W_{m, t}-W U_{m, t}\right) / T \\
& W S_{m}=\left\{\begin{array}{l}
0, W D_{m}>0 \\
W D_{m}, W D_{m}<0
\end{array}\right.
\end{aligned}
$$

where $E W_{m, t, x}$ represents excess water from upstream region $x$ for month $m$ in year $t$, million $\mathrm{m}^{3}$.

In the DP strategy, water shortage of the PRD is first calculated using Eq. 6. To provide enough water resource for the PRD, each upstream region releases the same absolute amount of water to the Delta. Therefore, new water uses in these upstream regions are the original projected water uses plus the mount of water released to the Delta. The rest of the calculations are the same as in the UP strategy. For the IrrP and ManP strategy, new water use for each region is generated by the OpenMORDM. Water shortage of the whole basin is then calculated based Eqs. 6 and 7.

\subsection{Economic Losses Calculation}

Economic losses are roughly estimated based on annual water shortage using Eq. 8 .

$$
E L=\sum_{i=1}^{N} \sum_{t=1}^{T}\left(W S \_I R R_{i, t} I_{i}+\frac{W S \_M A N_{i, t}}{M S W I_{2010} \times T C_{t}}\right)
$$

where WS_IRR ${ }_{i, t}$ and $W S \_M A N_{i, t}$ represents irrigation and manufacturing water shortage in the $i^{\text {th }}$ region in year $\mathrm{t}$, million $\mathrm{m}^{3} . I_{i}$ represents irrigation index. $M S W I_{2010}$ is the manufacturing structural water use intensity in the base year $2010, \mathrm{~m}^{3} / 1000$ international $\$ 2005 . T C_{t}$ is the annual technological change rate for the manufacturing factor. 


\section{Results}

\subsection{Water Scarcity in the PRB}

\subsubsection{Regional Water Use in the PRB}

Figure 2 presents different trends of future water use projected for the PRD and the upstream basin. The PRD's annual water use peaks around 2030 then curves. By 2050, the average total water use of the PRD increases by $10 \%$ to 22 billion $\mathrm{m}^{3}$ from 20 billion $\mathrm{m}^{3}$ in 2010.The upstream basin exhibits a steep increase of total water use in all three paths. The total water use of the upstream basin increases with more than $50 \%$ from 45 billion $\mathrm{m}^{3}$ in 2010 to 70 billion $\mathrm{m}^{3}$ in 2050 . Within the upstream areas, Guangxi and Guangdong (without the PRD) are the dominant water users, account for 54 and $30 \%$ total water use in 2010 and 43 and $33 \%$ total water use in 2050 respectively (Fig. 8 in Supplementary material 3).

(a) PRD-SSP1

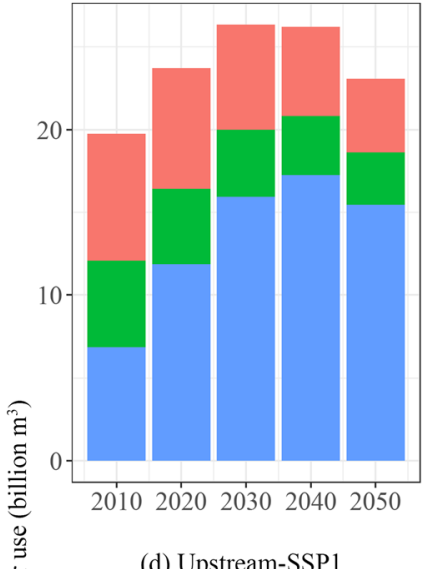

(d) Upstream-SSP1

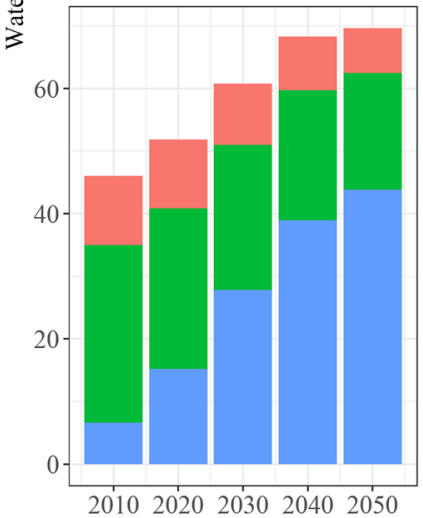

Domestic water use (b) PRD-SSP2

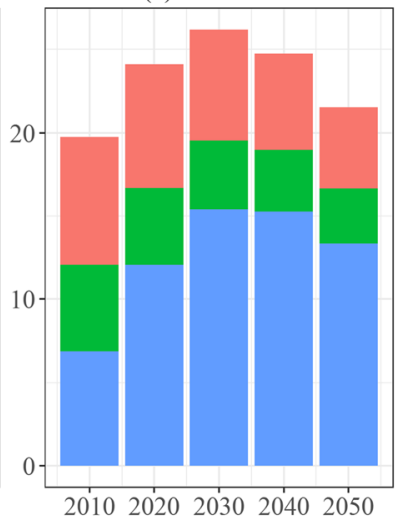

(e) Upstream-SSP2

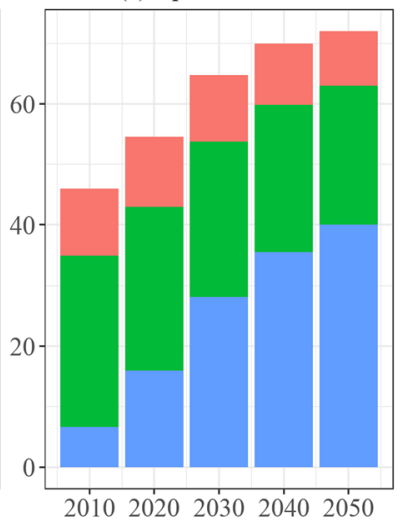

Irrigation water use (c) PRD-SSP3

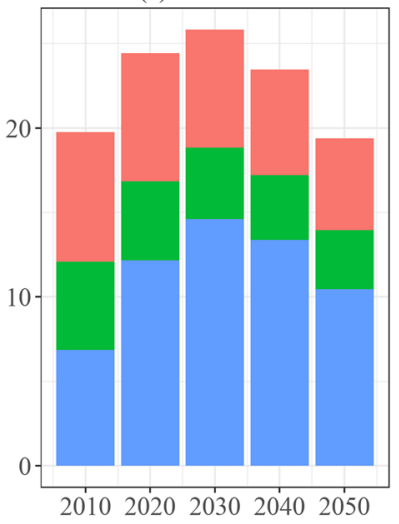

(f) Upstream-SSP3

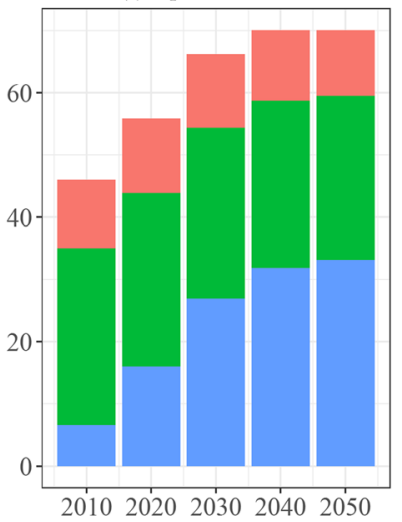

Manufacturing water use

Fig. 2 Sectorial water use projections for the PRD and the upstream PRB under different scenarios 


\subsubsection{Sectoral Water Use in the PRB}

The changes in future water use are largely driven by the manufacturing sector, the only sector where water use increases by 2050 , which is responsible for $45 \%$ of estimated total water use in the basin in 2050 .

Projections for the domestic and irrigation water use follow a consistent decreasing trend under all the scenarios across the PRB (Fig. 2). By 2050, domestic water use will decrease by $37 \%$ (PRD) and $19 \%$ (Upstream) due to a combination of population change and technological improvement. Irrigation water use will decrease by $36 \%$ (PRD) and $20 \%$ (Upstream) due to improved water use efficiency as a result of technological development, and a reduction of irrigated land. By 2050, the manufacturing sector dominates the total water use in the PRD, whereas irrigation water use still is a considerable fraction of the total water use in the upstream areas.

Large differences between the PRD and the upstream area exist due to different scale of irrigation sector. As the national SSP assumptions indicate, the upstream basin will continue to show rapid economic growth while retaining most of its irrigated lands. This results in a continuous increase of water use during the study period. Although the speed of increase levels off, our result do not show a clear saturation of total water use in the upstream basin by 2050. The Delta has its own development path, where the sectoral water use will maximize around 2030 and then gradually decrease. By 2050, the total water use in the PRD is comparable to the level of 2010.

\subsubsection{Water Availability Changes in the PRB}

The decadal changes of the water availability in the PRB show a decreasing trend from the 2010 s to 2040 s under RCP4.5 and 8.5 (Fig. 3a-b). At present about 280 billion $\mathrm{m}^{3}$ of water is available for the upstream and about 47 billion $\mathrm{m}^{3}$ is available for the PRD annually. This means that water use is presently at $25-30 \%$ of available amounts in the upstream and at 50 $60 \%$ in the downstream region. Under RCP4.5, water availability of the upstream regions and the PRD reduces by 15.2 and 1.69 billion $\mathrm{m}^{3}$ from the $2010 \mathrm{~s}$ to 2040 s respectively. The water availability under RCP8.5 for each decade is lower than the water availability under RCP4.5 for the whole basin.

\subsubsection{Water Shortages in the PRB}

Future water availability and water use in dry months projected for the PRB are compared. The comparison reveals water shortages exist for the period 2010-2050. The average decadal water shortages of the upstream regions and the PRD show an increasing trend, which is opposite to the trend of the water availability. The annual average water shortages for the whole upstream region and the PRD under the assumption that each region in the PRB is an independent system are shown in Fig. 3c-d. For the PRD, water shortages are around 500 million $\mathrm{m}^{3}$ per year. The upstream region's total water shortage is twice as much as the water shortage in the PRD. Results also show that water shortages under RCP8.5 are much higher than water shortages under RCP4.5 for the whole basin under all the SSPs. However, the differences in water shortage between different SSPs are not substantial in the PRD. For the upstream region, water shortages under SSP3 are clearly higher than water shortages under SSP1 and 2. 

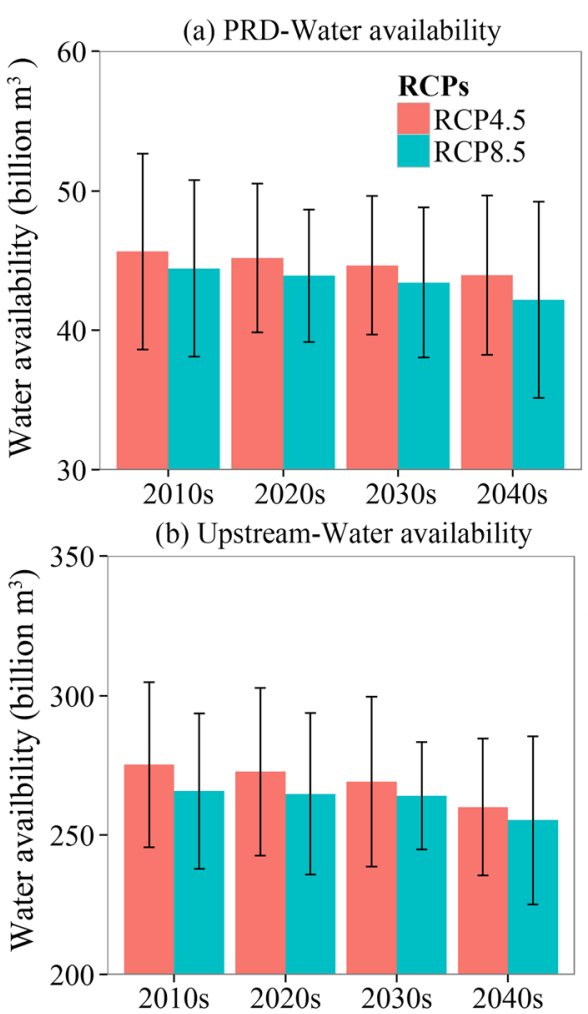

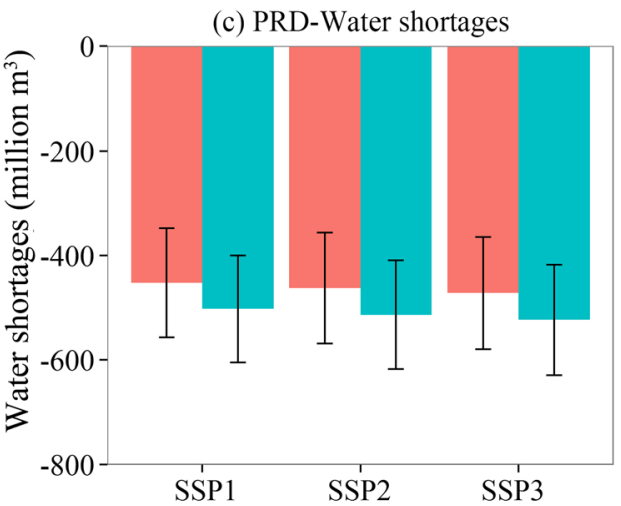

(d) Upstream-Water shortages

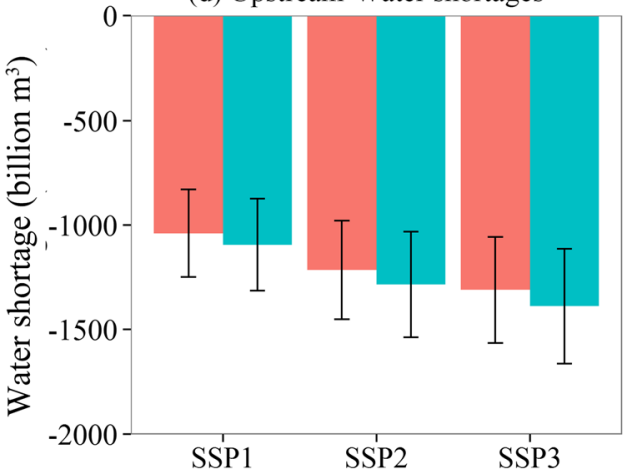

Fig. 3 Annual average water availability for each decade from 2010s to 2040s (a and b) and annual average water shortage during the period 2010-2050 under the RCPs (c and d). The error bars indicate minimum and maximum values of the five climate models

\subsection{Identifying Water Allocation Strategies}

Figure 4 illustrates an example how to identify the $\operatorname{IrrP}$ and ManP strategy using the OpenMORDM under RCP8.5 and SSP1. The OpenMORDM generates a set of alternative plans with different agricultural and manufacturing profits based on the two objectives and three constraints mentioned in Section 2.2. Since the main purposes of the IrrP and ManP strategy in this study are to pursue maximum agricultural and manufacturing profits, we manually select two plans that yield the highest agricultural and manufacturing profits as the IrrP and ManP strategy respectively. In other words, the OpenMORDM generates many possible plans, but in this study, we only discuss the most extreme plans. We use the same method to obtain the strategies for SSP2 and SSP3.

\subsection{Water Shortages under Different Water Allocation Strategies in the PRB}

Yunnan, Guangxi, Guangdong and the PRD are likely to face severe water shortages under the UP strategy (Fig. 5). Yunnan is the province with the highest water shortage, where an additional 300 million $\mathrm{m}^{3}$ of water is needed each month during January-April period for all the SSPs. For Guangxi, Guangdong and the PRD, water shortage is higher during the period of November-December than January-April. In the PRD, water shortage can reach up 


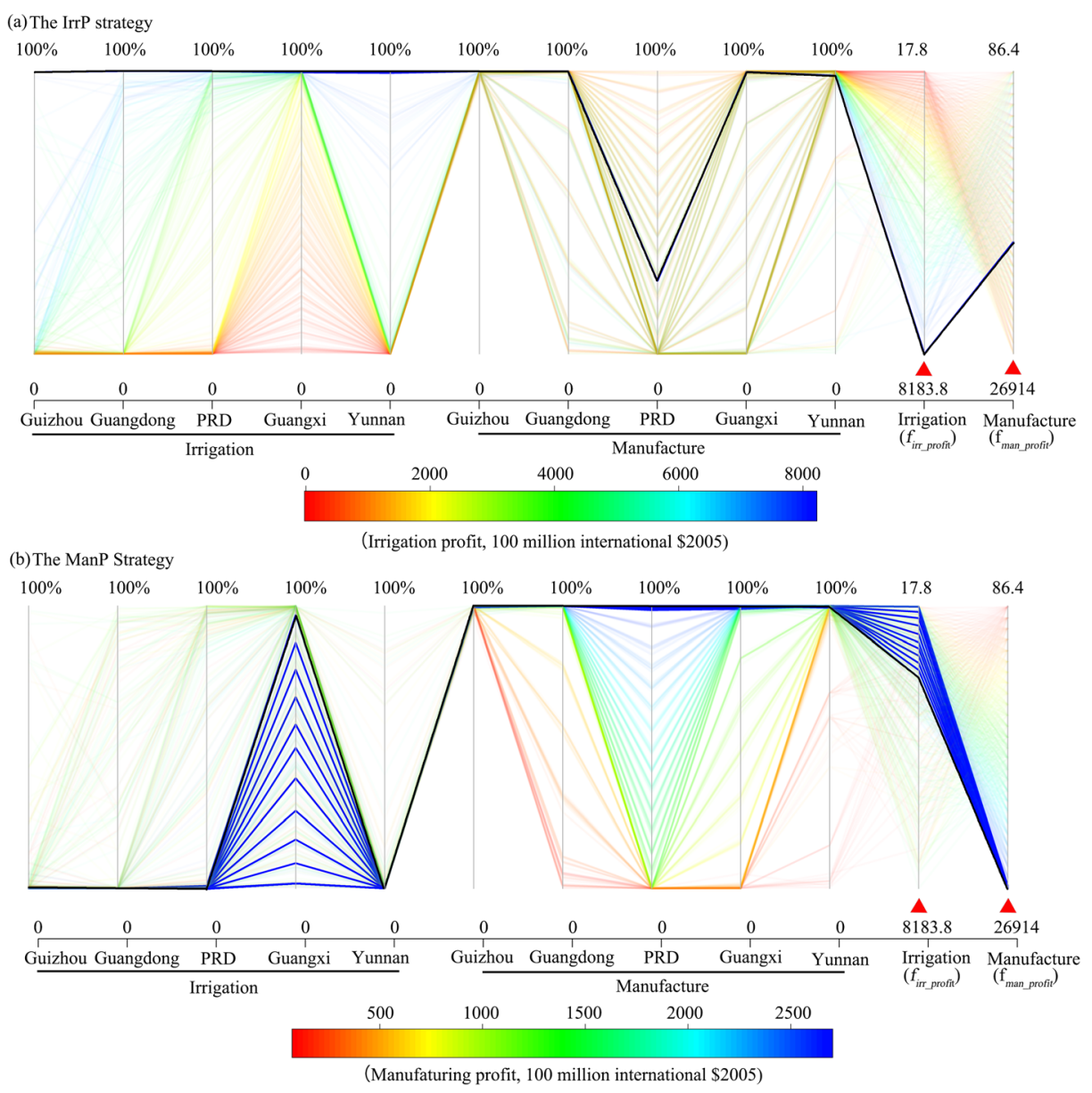

Fig. 4 Selection of the IrrP and ManP strategy under SSP1 and RCP8.5 (a) the IrrP strategy, (b) the ManP strategy. Each line represents an alternative plan where its intersections on the vertical axes represent the percentages of projected water use, which would be used in different regions for different purposes. The red triangles represent ideal values for the corresponding objectives. Plans are colored based on (a) irrigation and (b) manufacturing profits respectively. The black line is the selected plan

to 255 million $\mathrm{m}^{3}$ in December under SSP3. Results also show that only subtle differences in water shortage are found between different SSPs. Water shortages for all the regions except Guizhou are lower under SSP1 compared to SSP2 and 3.

Under the DP strategy, water shortages for all the upstream regions are larger compared to water shortages under the UP strategy, except for the PRD (Fig. 5). Additional water from the upstream regions is sufficient to supply all the water uses in the delta, but increases upstream shortages. Under SSP3, all the upstream regions expect Guizhou have the highest water shortages. In Guizhou, water shortages under SSP2 are higher than water shortages under SSP3. Figure 4 shows what percentages of projected irrigation and manufacturing water uses can be satisfied for each region under the IrrP and ManP strategy. The part that cannot be satisfied under the projected water availability is considered as water shortage of the region (see Section 2.3). Figure 6 shows the annual average water shortages for the whole basin under 


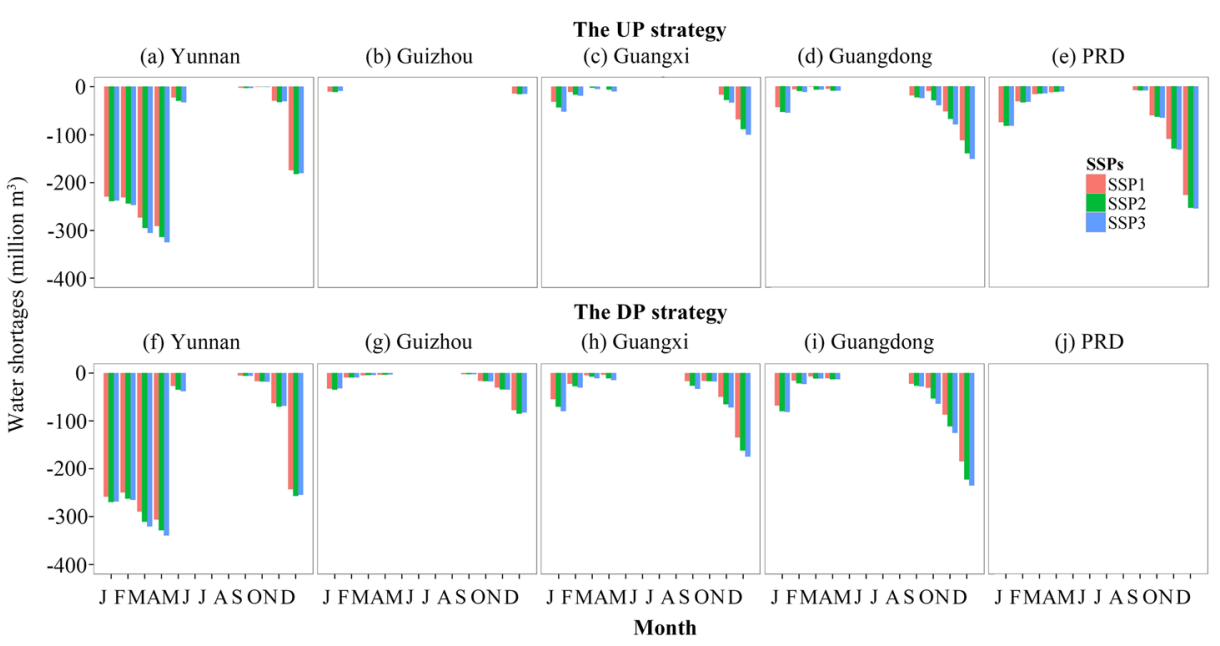

Fig. 5 Average monthly water shortages for different regions in the PRB under the upstream-prioritized and Delta-prioritized strategy during the period 2010-2050 (RCP8.5)

the SSPs. Water shortages range from 800 to 1500 million $\mathrm{m}^{3}$ under both IrrP and ManP strategy. Under SSP3, water shortage in the PRB is more severe than under SSP1 and SSP2. Under all three SSPs, water resources in the PRB are insufficient to satisfy both irrigation and manufacturing water uses.

\subsection{Economic Development under Different Water Allocation Strategies}

The economic profits of agriculture and manufacturing sector under the condition with no water stress are selected as the baseline, i.e. under the baseline, both the upstream and the PRD will achieve the socio-economic development suggested by the SSPs scenarios, regardless if enough water is available in future.

Figure 7 shows the average economic losses due to water shortages compared to the baseline under different water allocation strategies. The PRB has the highest economic losses under the IrrP strategy, up to $14 \%$ of the total projected GDP of the whole PRB in 2050. For two strategies that reflect the competition between the upstream regions and the PRD (the UP and DP strategy), the PRB has higher economic losses under the UP strategy. The economic

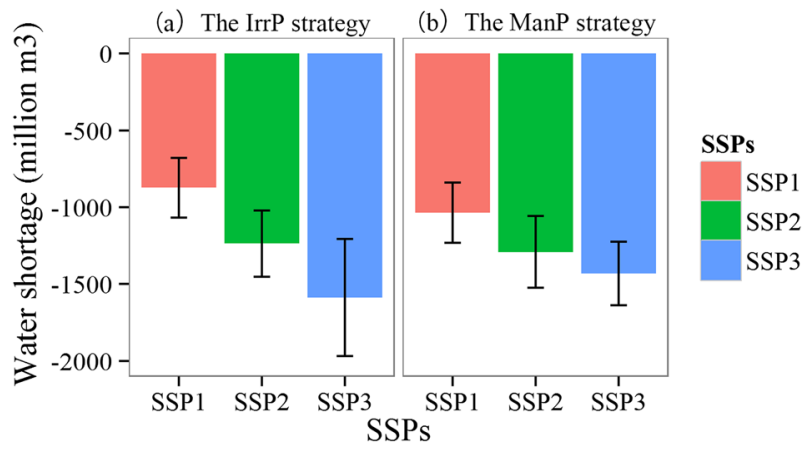

Fig. 6 Annual average water shortages under the IrrP and ManP strategy for the period 2010-2050 (RCP8.5) (a) the IrrP strategy, (b) the ManP strategy 
difference between the UP and DP strategy can reach up to 450 billion international $\$ 2005$ under SSP1. Results confirm that although the economic growth rate of the upstream region is projected to have a large increase in the future, it is still weak when facing the competition from the PRD. Another interesting finding is that the economic losses under the DP strategies is higher than economic losses under the ManP strategies. The result is different from what we have expected. The reason will be discussed in Section 4.

\section{Discussion}

\subsection{Projected Water Shortage}

This study shows that the PRB is likely to face water shortages under all projected scenarios (Fig. 3c-d). It is the result of both increasing water demand and decreasing water availability. For example, water demand of the upstream regions increases by 25 billion $\mathrm{m}^{3}$ from 2010 to 2050 . During the same period, the total water availability of these regions decreases by 10.38 billion $\mathrm{m}^{3}$ under RCP 8.5 . The increasing water demand contributes twice as much as the decreasing water availability to water shortage. The result is consistent with the work of Yang et al. (2008).

(a) The UP strategy

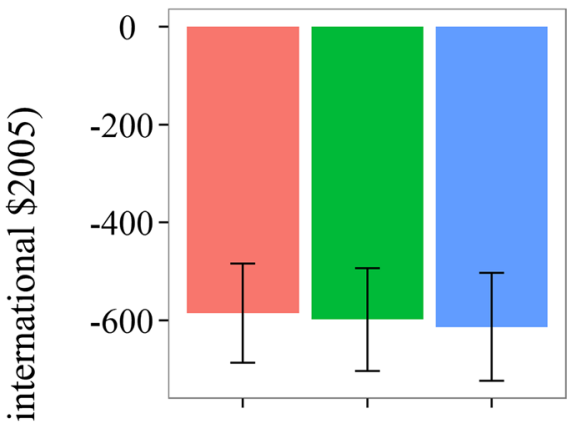

(c) The IrrP strategy

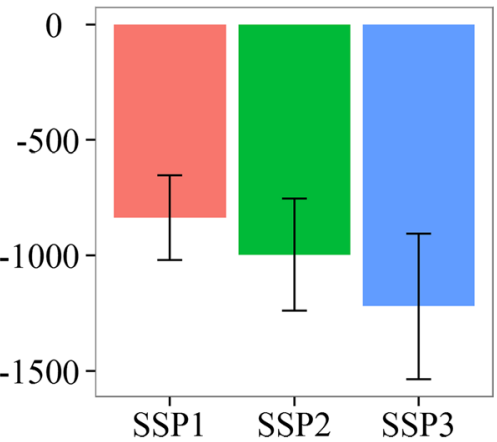

(b) The DP strategy

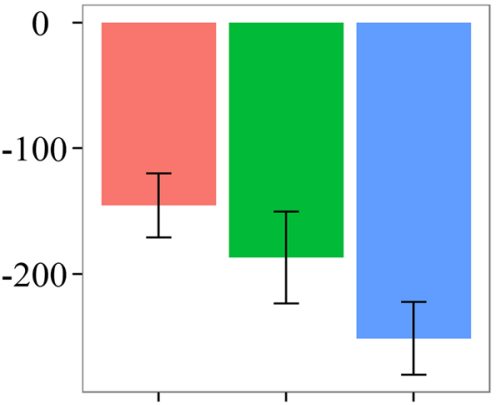

(d) The ManP strategy

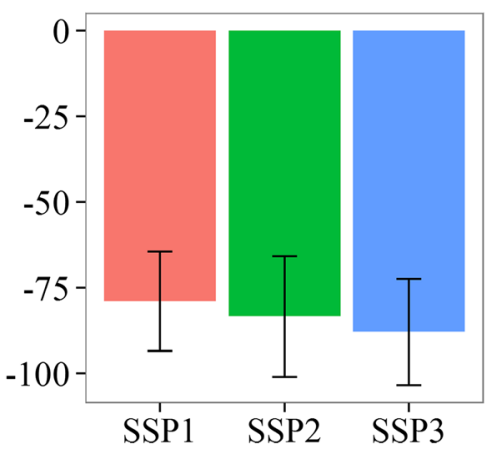

SSPs SSP1 SSP2 SSP3

Fig. 7 Average economic losses for the whole Pearl River basin under four different water allocation strategies in 2050 (RCP8.5) (a) the upstream-prioritized, (b) the PRD-prioritized, (c) the irrigation-prioritized, and (d) the manufacture-prioritized strategy. Note different scale of y-axis of the different panels 
Figure 3 suggests the differences in water shortage between RCPs are larger than differences between SSPs. The error bars in Fig. 3 indicate that uncertainty in GCMs are larger than uncertainty in RCPs. To sum up, uncertainty in SSPs < RCPs < GCMs. Our previous study explored uncertainties existed in different GCMs and RCPs (Yan et al. 2015). In this study, more attentions were paid to the three SSPs. Differences in water shortage between different SSPs are not significant based on our water use projections. Because the study period is relatively short, during which the socio-economic development under different SSPs pathways are not diverged significantly from each other. The water shortages are slightly higher under SSP3 (Fig. 3c-d). This is consistent with the narrative of the shared socio-economic pathways. Low water use intensity due to slow technological change, together with high domestic water demand, make SSP3 the most water consuming scenario.

\subsection{Impact of Different Water Allocation Strategies on Water Use}

In the real world, selection of water allocation plans requires stakeholders from different sectors to reach a compromise between the objectives. All the water users in the PRB should be given a fair treatment. But in this paper, only the most extreme plans were discussed. Performance of the four water allocation strategies was evaluated. Results show that none of the prioritization strategy is sufficient to avoid all economic losses caused by water scarcity in the PRB (see Section 3.4). Prioritizing water for the delta and manufacture sector are the most profitable water allocation strategies.

The purpose of the "Key Reservoirs Operational Project for the Pearl River Basin" is to transfer upstream fresh water to the delta to repel saltwater intrusion and ensure water supply safety for the delta (Xie 2007). This policy is actually a delta-prioritized strategy. In this study, we also defined a delta-prioritized strategy, where each upstream province gives the same absolute amount of additional water to the PRD. In this case, the pressure for Yunnan is much higher than Guangxi. Figure 5 show that Yunnan province is likely to face the worst water scarcity compared to other regions in the PRB, especially in spring. This result is consistent with some previous studies (Jia and Pan 2016; Wang and Meng 2013). In Yunnan, drought in spring is a major and frequent natural disaster especially over the last three decades (Abbas et al. 2014). Hence, it is likely that Yunnan does not have the ability to provide more water for the downstream regions in the future.

\subsection{Economic Losses under Different Water Allocation Strategies}

Figure 7 shows that the ManP strategy has lower economic losses compared to the deltaprioritized strategy. It is because the additional water from the upstream regions is also used to satisfy the agricultural water uses in the Delta under the delta-prioritized strategy. In 1979, the area of irrigated land in the PRD was $1.38 \times 10^{4} \mathrm{~km}^{2}$, accounting for $25.5 \%$ of the total area. The proportion of irrigated land in the PRD decreased from $25.5 \%$ in 1979 to $16 \%$ in 2009 , accompany with a rapid increase of construction land (Liu et al. 2016). In Section 3.1, agricultural water uses in 2050s reduce around $60 \%$ compared to 2010 s, due to improved water use efficiency and a reduction of irrigated land. Nevertheless, the agricultural water use still accounts for more than $10 \%$ total water use in 2050s (Fig. 2). Water allocation between upstream regions and the $\mathrm{PRD}$ requires a compromise between economic profits and equity in the future. In addition, food security is also a high priority in China. Water resources tend to be transferred from low-value agricultural uses to high-value manufacturing uses in the PRB. In 
many parts of the PRB, Water shortages are limiting agricultural development (Khan et al. 2009). Since the PRB is one of the most important granaries in China, the local government must first consider the increasing food demands before implementing a policy.

\subsection{Recommendations for Water Management in the PRB}

It should be noted that water shortages in the PRB are seasonal events. There is sufficient water supply for the PRB during the wet season. However, storing large amount of water in reservoirs may lead to increasing flood risk as more than $80 \%$ of streamflow in the PRB occurs during the wet season. Even so the reservoirs should play a very important role in storing extra water from the wet season for water use in the dry season. This requires the establishment of a better water resources and use monitoring system based on ground observations and satellite images, better predictions for future climate, and advanced technologies to develop water allocation strategies. Our results show that manufacturing water use plays a dominant role in total water use in the PRD. Recently, traditional manufacture with high water consumption, high water pollution and low efficiency still occupies a large proportion in the PRB. There is an urgent need for industrial restructuring, transformation and upgrading in the PRB.

\subsection{Some Study Limitations and Outlook}

The primary limitation comes from the missing sectors and detailed sub-sectoral information. Data limitations for the thermo-electricity sector make it very difficult to associate this sector with the SSP storylines in a consistent way. However, this maybe more important for water quality (i.e. temperature) considerations than for water quantity stress, since most of cooling water intake returns to the river again (Fthenakis and Kim 2010).

Moreover, uncertainty lies in both estimation of manufacturing water use intensity and manufacturing products. Manufacturing water use intensity and economic gains heavily depend on the structural composition of this sector and the corresponding technology it adopts. However, no sub-sector water-use data is available. It is unlikely that the industrial structure in the upstream basin will remain the same for the coming few decades given its fast industrialization process. Thus, the current projection of manufacturing water uses and products may need to be updated when future long term plans become available.

\section{Conclusion}

Results show that future water use is much higher than water supply. Large scale increases in water use are mainly from manufacture factor in the upstream regions. Furthermore, differences in water uses or water shortages are not substantial between the SSPs for the whole basin. Under SSP3, the basin has the highest water shortage. Results also show that almost all the regions in the PRB are likely to face water shortage under the four water allocation strategies due to combined effects of climate change and socio-economic development. The delta region only has sufficient water resources under the delta-prioritized strategy. The economic losses differ greatly under the four strategies. Prioritizing the delta region or manufacturing production would result in lower economic losses than the other two strategies, whereas the economic loss is the highest when water for irrigation has the priority. All four 
water allocation strategies are insufficient to solve the water scarcity in the PRB. However, all of them are rather extreme strategies. Development of water resources management strategies requires a compromise between different water users. In addition, new technologies and increasing water use efficiency are important to deal with future water shortage in the PRB.

Acknowledgments This work was financially supported by Joint Scientific Thematic Research Programme "Working with Water: adaptive land use and water management in the Pearl River Delta under climate change and sea level rise" (the Netherlands Organisation for Scientific Research, No. 842.00.002), National Natural Science Foundation of China (No. 41330751, 41561144012 and 41661144030), External Cooperation Program of Chinese Academy of Sciences (No. GJHZ1019) and China Postdoctoral Science Foundation (No. 2013M540135).

Open Access This article is distributed under the terms of the Creative Commons Attribution 4.0 International License (http://creativecommons.org/licenses/by/4.0/), which permits unrestricted use, distribution, and reproduction in any medium, provided you give appropriate credit to the original author(s) and the source, provide a link to the Creative Commons license, and indicate if changes were made.

\section{References}

Abbas S, Nichol J, Qamer F, Xu J (2014) Characterization of drought development through remote sensing: a case study in Central Yunnan, China. Remote Sens 6:4998-5018. https://doi.org/10.3390/rs6064998

Alcamo J, FlÖRke M, MÄRker M (2007) Future long-term changes in global water resources driven by socioeconomic and climatic changes. Hydrol Sci J 52:247-275. https://doi.org/10.1623/hysj.52.2.247

Biswas AK (2004) Integrated water resources management: a reassessment. Water Int 29:248-256. https://doi. org/10.1080/02508060408691775

Cai G, Du M, Liu Y (2011) Regional drought monitoring and analyzing using MODIS data — a case study in Yunnan Province. In: Li D, Liu Y, Chen Y (eds) Computer and computing Technologies in Agriculture IV: 4th IFIP TC 12 conference, CCTA 2010, Nanchang, China, October 22-25, 2010, selected papers, Part II. Springer Berlin Heidelberg, Berlin, Heidelberg, pp 243-251. doi:10.1007/978-3-642-18336-2_29

Fthenakis V, Kim HC (2010) Life-cycle uses of water in U.S. electricity generation. Renew Sustain Energy Rev 14:2039-2048. https://doi.org/10.1016/j.rser.2010.03.008

Ge M, Wu FP, Chen XP (2017) A coupled allocation for regional initial water rights in Dalinghe Basin, China. Sustainability 9:428. https://doi.org/10.3390/su9030428

Hadka D, Herman J, Reed P, Keller K (2015) An open source framework for many-objective robust decision making. Environ Model Softw 74:114-129. https://doi.org/10.1016/j.envsoft.2015.07.014

Jalan J, Ravallion M (2000) Is transient poverty different? Evidence for rural China. J Dev Stud 36:82-99. https://doi.org/10.1080/00220380008422655

Jia H, Pan D (2016) Drought risk assessment in Yunnan Province of China based on wavelet analysis. Adv Meteorol 2016(1):-10. https://doi.org/10.1155/2016/1579415

Khan S, Hanjra MA, Mu J (2009) Water management and crop production for food security in China: a review. Agric Water Manag 96:349-360. https://doi.org/10.1016/j.agwat.2008.09.022

Lai HH (2002) China's western development program: its rationale, implementation, and prospects. Modern China 28:432-466

Liu Z, Huang H, Werners SE, Dan Y (2016) Construction area expansion in relation to economic-demographic development and land resource in the Pearl River Delta of China. J Geogr Sci 26:188-202. https://doi. org/10.1007/s11442-016-1262-7

Liu D, Liu WT, Fu Q, Zhang YJ, Li TX, Imran KM, Abrar FM (2017) Two-Stage Multi-Water Sources Allocation Model in Regional Water Resources Management under Uncertainty. Water Resources Management:1-19. https://doi.org/10.1007/s11269-017-1688-4

O’Neill BC, Kriegler E, Ebi KL, Kemp-Benedict E, Riahi K, Rothman DS, van Ruijven BJ, van Vuuren DP, Birkmann J, Kok K, Levy M, Solecki W (2015) The roads ahead: narratives for shared socioeconomic pathways describing world futures in the 21st century. Glob Environ Chang 42:169-180. https://oi. org/10.1016/j.gloenvcha.2015.01.004

Oki T, Kanae S (2006) Global hydrological cycles and world water resources. Science 313:1068-1072. https://doi.org/10.1126/science.1128845 
Pastor AV, Ludwig F, Biemans H, Hoff H, Kabat P (2013) Accounting for environmental flow requirements in global water assessments. Hydrology \& Earth System Sciences 18:14987-15032. https://doi.org/10.5194 /hess-18-5041-2014

Piao S, Ciais P, Huang Y, Shen Z, Peng S, Li J, Zhou L, Liu H, Ma Y, Ding Y, Friedlingstein P, Liu C, Tan K, Yu Y, Zhang T, Fang J (2010) The impacts of climate change on water resources and agriculture in China. Nature 467:43-51. https://doi.org/10.1038/nature09364

PRWRC (2001) Pear River Water Resource Bulletin (in Chinese). Pearl River Water Resources Commission of the Ministry of Water Resources. http:/www.pearlwater.gov.cn/xxcx/szygg/01gb/. Accessed 08 Jan 2018

PRWRC (2015) Pear River Water Resource Bulletin (in Chinese). Pearl River Water Resources Commission of the Ministry of Water Resources. http:/www.pearlwater.gov.cn/xxcx/szygg/15gb/. Accessed 08 Jan 2018

van Vuuren DP, Edmonds J, Kainuma M, Riahi K, Thomson A, Hibbard K, Hurtt GC, Kram T, Krey V, Lamarque JF, Masui T, Meinshausen M, Nakicenovic N, Smith SJ, Rose SK (2011) The representative concentration pathways: an overview. Clim Chang 109:5-31. https://doi.org/10.1007/s10584-011-0148-Z

Wang L, Chen W (2014) A CMIP5 multimodel projection of future temperature, precipitation, and climatological drought in China. Int J Climatol 34:2059-2078. https://doi.org/10.1002/joc.3822

Wang J, Meng Y (2013) An analysis of the drought in Yunnan, China, from a perspective of society drought severity. Nat Hazards 67:431-458. https://doi.org/10.1007/s11069-013-0572-7

World Bank (2015) East Asia's changing urban landscape : measuring a decade of spatial growth. Washington, DC doi:10.1596/978-1-4648-0363-5

Xie S (2007) Comments on Pearl River key reservoir group water allocation scheme and technology (in Chinese). Pearl River 28:16-18

Yan D, Werners SE, Ludwig F, Huang HQ (2015) Hydrological response to climate change: The Pearl River, China under different RCP scenarios. Journal of Hydrology: Regional Studies 4(Part B):228-245. https://doi.org/10.1016/j.ejrh.2015.06.006

Yang ZF, Zeng Y, Cai YP, Tan Q (2008) An integrated game-theory based model for trans-boundary water resources Management in North China: a case study in the Guanting Reservoir Basin (Grb), Beijing. Int J Softw Eng Knowl Eng 18:461-483. https://doi.org/10.1142/s021819400800374x

Yao MT, Yan D, Kabat P, Huang H, Hutjes RWA, Werners SE (2016) Analysing monthly sectorial water use and its influence on salt intrusion induced water shortage in urbanized deltas. Sustainable Cities and Society 26: 255-263. https://doi.org/10.1016/j.scs.2016.06.020

Yao M, Tramberend S, Kabat P, Hutjes RWA, Werners SE (2017) Building regional water-use scenarios consistent with global shared socioeconomic pathways. Environmental Processes 4:15-31. https://doi. org/10.1007/s40710-016-0203-x

Zheng JJ, Business SO, University H (2016) Did western development program improve carbon green contribution coefficient in China's western region?__ an empirical analysis on difference-in-difference method (in Chinese). Economic Survey 33:26-31

Zhong SY (2004) Water Transfer and Migration:Another Perspective of Proper Allocation of Population and Water Resource (in Chinese). Population \& Economics 147:55-59 